Citation: D.E. Moser (2021) Crystalline Stenonian Time Features from Earth and Beyond. Substantia 5(1) Suppl.: 99-114. doi: 10.36253/Substantia-1281

Copyright: (c) 2021 D.E. Moser. This is an open access, peer-reviewed article published by Firenze University Press (http://www.fupress.com/substantia) and distributed under the terms of the Creative Commons Attribution License, which permits unrestricted use, distribution, and reproduction in any medium, provided the original author and source are credited.

Data Availability Statement: All relevant data are within the paper and its Supporting Information files.

Competing Interests: The Author(s) declare(s) no conflict of interest.

\section{Crystalline Stenonian Time Features from Earth and Beyond}

\author{
Desmond E. Moser \\ Department of Earth Sciences, University of Western Ontario, London, Ontario, Canada; \\ N6A 5B7 \\ E-mail: desmond.moser@uwo.ca
}

\begin{abstract}
The writings of Niels Stensen (Steno) on mineral growth and modification in his Prodromus, together with his work on time and process in other solids, are here synthesized as five classes of time features defined by changes in the visible continuity of either or both chemistry and orientation. This organization highlights Steno's implicit recognition of the fractal, scale-invariant nature of natural time features with regard to space, time, and material. The effectiveness of this Stenonian geochronology framework is demonstrated down to atom scale with modern case studies of the U-Pb geochronology of mineral zircon in samples originating from the Earth, Moon, and Mars spanning most of solar system history. Recently discovered nano-scale features, here termed chronostructures, were intimated by Steno in his corpuscular view of mineral behaviour. The remarkable advances in the Prodromus are seen here as resulting from the intersections of Steno's highly attuned approach to visual perception, his adoption of Stoic (Senecan) ethics early in his career to guide his natural philosophy, and the influence of the Galilean scientific environment of Florence. It is argued that the scale-invariant, intensive quality of Stenonian geochronology makes it an invaluable check on the accuracy of absolute, extensive measurements of geologic time by chemical or isotopic means. In this way Steno's scientific legacy continues to propel human understanding of how we see our place in time.
\end{abstract}

Keywords: Steno, crystal, zircon, geochronology, fractal, Stoic.

\section{INTRODUCTION:}

The geological writings of the famed anatomist Niels Stensen, mostly expressed in his "The Prodromus to a Dissertation on a Solid Naturally Contained Within a Solid" (hereon referred to as the Prodromus), ${ }^{1}$ have been seen as foundational to the current fields of stratigraphy, palaeontology and crystallography through his elucidation of the principles of sedimentary superposition, the organic origin of fossils, and the law of angular con-

\footnotetext{
${ }^{1}$ N. Stensen, De Solido Intra Solidum Naturaliter Contento Dissertationis Prodromus, Florence, Stella, 1669 (Prodromus in following notes). English translation in T. Kardel, P. Maquet, Nicolaus Steno, Biography and Original Papers of a 17th Century Scientist, $1^{\text {st }}$ edition, Heidelberg, Springer, 2013 (K\&M in notes below), pp. 621-660,
} 
stancy in crystals, respectively. Steno's 'founder' status, however, is seen by some historians of science as anachronistic, ${ }^{2}$ given that his authorship of these ideas was ignored for more than a century before acknowledgement in later retrospectives of geography and geology. ${ }^{3,4}$ More recent historians of science have commented that Steno's Prodromus was principally an advance in the cognition of geologic time. ${ }^{5,6}$ Steno's novel and detailed descriptions of mineral growth have received renewed attention ${ }^{7}$, and in this paper I propose that his influence on the field of geochronology likewise merits greater recognition, particularly in light of the continuing application of Stenonian methods. With Steno's mineralogy as a starting point, I have used his observations of time information in all solids to derive a classification scheme for Steno's vision-based geochronology. The modern relevance of this scheme is illustrated with microscopy case studies, down to atom scale, of the weakly radioactive geochronology of mineral zircon in samples from Earth and other planetary bodies spanning most of solar system history. This is followed by a consideration of Steno's method of observational science in the context of his European education and association with the Galilean Accademia del Cimento to explore reasons why Steno was able to perceive geologic time hidden from most others. Finally, the continuing importance of Steno's approach to the accuracy of both relative and absolute geochronology is discussed. It is hoped that, as it did for me, this treatment links Earth scientists and geochronologists more clearly to our observational and philosophic roots as well as to an awareness of the 17th century brilliance of Steno working in the Galilean tradition.

\section{Relative and absolute geochronology - then and now}

Geochronology is taken here to be the science of measuring time information from natural materials and

\footnotetext{
${ }^{2}$ M. J. S. Rudwick, The Meaning of Fossils. Episodes in the History of Palaeontology. London, MacDonald, London, \& New York, American Elsevier Inc., 1972, 287 pp.

${ }^{3}$ N. Desmarest, Géographie physique. 4 vols. Paris, 1794 [Encyclopédie méthodique].

${ }^{4}$ C. Lyell, Principles of Geology: being an attempt to explain the former changes of the Earth's surface, by reference to causes now in operation. London, John Murray, 1, 1830.

${ }^{5}$ K., von Bülow (1971) Stenos aktualistisch-geologische Arbeitsweise, Scherz, Dissertations on Steno as Geologist. Acta Historica Naturalium et Medicinalium, 1971, 149-162; as cited in ref. 1 (K\&M).

${ }^{6}$ S. J. Gould, The titular bishop of Titiopolis. Natural History, 1981, 90, pp. 20-24; reprinted in Hen's teeth and horse's toes, New York, Norton's Paperback, 1983, pp. 69-78.

${ }^{7}$ A. Authier, Early Days of X-ray Crystallography. International Union of Crystallography/Oxford University Press, 2013, pp. 299-305.
}

to be of two types; relative, establishing the numerical order of events, and absolute, the age of an event or interval referenced to units of years. In the age of Steno, and particularly in the Prodromus, the relative and absolute times for events in Earth history were based on natural philosophy and biblical scripture, respectively, and were not seen to intersect or conflict as they were derivatives of independent logic systems ${ }^{2,8}$ with which Steno presented faith and natural history as separate domains of knowledge. ${ }^{9}$ Steno's natural philosophy was likely influenced by that of Aristotle, in view of his adaptation of Aristotelian form and argument in his early work on hot springs, De Thermis ${ }^{10}$. Sambursky provides a concise summary of Aristotelian philosophy regarding relative and absolute time:

Aristotle's definition "time is number of motion in respect of 'before' and 'after"-expresses both the association of time with change and the possibility of enumerating this change. It is also evident from his analysis that he realized that the prerequisite for time measurement is a clock, i.e., a periodic mechanism, and that the revolution of the celestial sphere, being a regular circular motion, is the best measure of time "because the number of it is the best known". ${ }^{11}$

As noted by many authors, Steno declined assigning absolute ages directly to natural solids as on this topic "nature says nothing", ${ }^{12}$ but he nevertheless played a pioneering role in ordering sedimentary strata in respect to the directional arrow of time. ${ }^{13}$

The 19th century saw the ascendence of absolute geochronology after the discovery of the laws of radioactivity and techniques for measuring ratios of elements and their isotopes in rocks and minerals. ${ }^{14}$ The first measurement of the absolute ages of sedimentary strata is widely attributed to Holmes ${ }^{15}$ who compared

\footnotetext{
${ }^{8}$ A. H., Cutler, Nicolaus Steno and the problem of deep time, in The Revolution in Geology from the Renaissance to the Enlightenment (Ed. G. D. Rosenberg), Geological Society of America Memoir, 2009, 203, p. 143-148.

${ }^{9}$ J. Bek-Thomsen, Steno's Historia. Methods and Practices at the Court of Ferdinando II, in Steno and the Philosophers (Eds.: R. Andrault, M. Lærke), Brill, Leiden, 2018, p. 233-258.

${ }^{10} \mathrm{R}$. Rappaport, When geologists were historians, Ithaca and London, Cornell University Press, 1997, 320 pp.

${ }^{11}$ S. Sambursky, Physics of the Stoics. Princeton, NJ, Princeton University Press, 1987, 166 pp.

${ }^{12}$ N. Stensen, Prodromus, in ref. 1 (K\&M), p. 654.

${ }^{13} \mathrm{G}$. Kravitz, The geohistorical time arrow: from Steno's stratigraphic principles to Boltzmann's past hypothesis, Journal of Geoscience Education, 2014, 62, p. 691-700.

${ }^{14}$ E. Rutherford, E., \& F. Soddy, J. Chem. Soc., 1902, 81, p. 837; reprinted in Phil. Mag., 1902, 4, p. 370; 1903, 5, p. 576.

${ }^{15} \mathrm{~A}$. Holmes, The association of lead with uranium in rock-minerals, and its application to the measurement of geological time. Proceedings of the Royal Society of London A, 1911, 85, p. 248-256.
} 
the relative (Stenonian) geochronology of a section of early Paleozoic sediments in Norway to absolute ages calculated from the $\mathrm{U}$ and $\mathrm{Pb}$ abundances in minerals (including zircon $\left(\mathrm{ZrSiO}_{4}\right)$ ) from inter-layered and cross-cutting igneous (once molten) rock bodies. Critically, Holmes established the premise of the "closed system" for absolute methods; stipulating that an age measurement is only accurate if the sampled volume has remained closed to chemical alteration since its production aside from change due to radionuclide decay. In this light, and in the terminology of thermodynamics, every absolute geologic age is an extensive property of a solid. The extent of the systems in Holmes' pioneering work were mineral grains containing $U$ and its radiogenic $\mathrm{Pb}$. As we will see, it is due to this extensive property that the accuracy of absolute methods relies, ultimately, on Steno's relative approach.

Minerals are defined by the International Mineralogical Association as the inorganic building blocks of rocks, each characterized by a particular chemical composition and a defined crystal structure. These commonly occur as polyhedral bodies such as the $\mathrm{cm}$-scale specimens described in the Prodromus. Steno classed minerals as "angular solids", and focused on samples of "crystal" (quartz) and "iron" (hematite, pyrite) which he collected from the Tuscany region, Elba, and other localities in central Europe ${ }^{16}$. Absolute geochronology using the U-Th- $\mathrm{Pb}$ decay chains has become the benchmark for calibrating the time scale for the Earth ${ }^{17}$ and solar system, ${ }^{18}$ and the U-bearing mineral zircon plays a major role. ${ }^{19}$

Zircon occurs widely in the crusts of rocky planets, mostly as microscopic grains forming accessory components in rocks over a depth range on the order of 100 kilometres. The primary features of each grain can withstand erosion, mountain building events, transport in magmas, plate tectonic cycles, and meteorite impacts; all the while accumulating either or both external and internal features that bear witness to these events. ${ }^{20}$ Zircon crystals commonly have the width of a human hair, an order of magnitude smaller than Steno's cm-scale samples (Fig. 1), yet zircon grains have the distinction of being the old-

\footnotetext{
${ }^{16} \mathrm{~N}$. Stensen, in ref. 1 (K\&M), p. 208.

${ }^{17}$ Y., Amelin, et al., Lead isotopic ages of chondrules and calcium-aluminum-rich inclusions. Science, 2011, 297, pp. 1678-1683.

${ }^{18}$ J. M. Connelly et al., Chronology of the solar system's oldest solids. The Astrophysical Journal, 2008, 675, p. L121-L124.

${ }^{19} \mathrm{~B}$. Schoene, U-Th-Pb Geochronology, in Treatise on Geochemistry, K. Turekian, H. Holland (Eds.), 2014, 4, Elsevier Oxford, p. 341-378.

${ }^{20}$ F. Corfu, J. M. Hanchar, P. W. O. Hoskin, P. Kinny, Atlas of zircon textures. Reviews in mineralogy and geochemistry, 2003, 53, p. 469-500.
}

est known pieces of the Earth, ${ }^{21}$ Moon ${ }^{22}$ and Mars. ${ }^{23}$ Zircon also has a different crystal structure in comparison to Steno's quartz (tetragonal vs. hexagonal) however it exhibits a similar, long-prismatic habit such that it is weakly to strongly columnar, sharing "intermediate" (prismatic) and "terminal" (pyramidal) faceting reported by Steno. ${ }^{24}$ Zircon exhibits internal zoning when a cross-sectional surface is imaged with a scanning electron microscopy and a cathodoluminescence detector (SEM-CL). ${ }^{25}$ These zones are analogous to the colour changes noted by Steno in his quartz cross sections of "the plane in which the axis of the crystal lies"26 (Fig 1). Steno's cross-sectional depictions were novel in his time, marking a transition from 'organic' to 'mechanical' mineralogy', ${ }^{27}$ whereas such cross-sectional crystal imaging is now a routine component of petrology and absolute zircon geochronology.

\section{Previous work on Stenonian geochronology}

The framework which Steno describes in the Prodromus for interpreting the Earth resolved not only the immediate question of the nature of fossils, and discriminating their found location from their place of production, but presented a logic structure for identifying geologic time sequences from features discernible in solids. ${ }^{28}$ Steno's authorship of this structure was largely ignored among later theories of the Earth although his concepts and ideas carried on in the work of others such as Leibniz ${ }^{29}$ or were tested and transmitted by later Italian geologists. ${ }^{30}$ Receiving most attention was his princi-

${ }^{21}$ J. W. Valley, A. J. Cavosie, T. Ushikubo, D. A. Reinhard, D. F. Lawrence, D. J. Larson, P. H. Clifton, T. F. Kelly, S. A. Wilde, D. E. Moser Hadean age for a post- magma-ocean zircon confirmed by atom-probe tomography. Nature Geosci., 2014, 7, p. 219-223.

22 A. Nemchin, N. Timms, R. Pidgeon, et al. Timing of crystallization of the lunar magma ocean constrained by the oldest zircon. Nature Geosci., 2009, 2, p. 133-136.

${ }^{23}$ L. C. Bouvier et al., Evidence for extremely rapid magma ocean crystallization and crust formation on Mars. Nature, 2018, 558, p. 586-589.

${ }^{24}$ N. Stensen, in ref. 1 (K\&M), p. 639.

${ }^{25}$ J. M. Hanchar, C. F. Miller, Zircon zonation patterns as revealed by cathodoluminescence and backscattered electron images: implications for interpretation of complex crustal histories. Chemical Geology, 1993, 110, p. 1-13.

${ }^{26}$ N. Stensen, in ref. 1 (K\&M), p. 659.

${ }^{27}$ W. R. Albury, D. R. Oldroyd, From Renaissance mineral studies to historical geology, in the Light of Michel Foucault's "The Order of Things". The British Journal for the History of Science, 1977, 10, pp. 187215.

${ }^{28}$ M. J. S. Rudwick, The meaning of fossils. Episodes in the history of palaeontology. London, MacDonald, London, \& New York, American Elsevier Inc., 1972, 287 p.

${ }^{29}$ D. Garber, Steno, Leibniz, and the history of the world, in ref. 8, p. 201-232.

${ }^{30} \mathrm{~S}$. Dominici, Steno, Targioni and the two forerunners. Journal of Mediterranean Earth Sciences, 2009, 1, p. 101-110. 
ple of 'moulding'31 which had been denoted in the 18th century by Desmarest as Steno's "Premier Principé". ${ }^{32}$ Among the most detailed modern assessments of Steno's work regarding relative geochronology is that of Hans$\mathrm{en}^{33}$ who recognized in Steno's writings the "cognition criteria" of chronology, recognition (i.e. resemblance), and preservation. Chronology was subdivided into the principles of moulding and intersection. Moreover, two underlying axioms related to the quality of orientation were proposed in terms of "conformity," and "disconformity." Steno's interpretation of what had been viewed previously as "signs" in natural materials ${ }^{34}$ were termed "structural", underpinning a further five principles of geological interpretation leading to "back-stripping" to reconstruct crustal dynamics over time. These organizations of Steno's work on solids were interpreted predominantly from his macroscopic observations of sediments, and, while valid and self-consistent, did not incorporate many of Steno's observations of minerals and mineralized bodies such as agate ("incrustations"). When these too are considered, and paired with Steno's atomistic (corpuscular) view of crystals, ${ }^{35}$ additional Stenonian insights become apparent.

\section{METHOD AND MATERIALS}

The Prodromus has been called "a complex and odd little book", ${ }^{36}$ and in his introductory text Steno does apologize to his patron for any seeming disorganization due to the constraints of time and travel. My analysis initially relied on the English translation of the Prodromus by Winter ${ }^{37}$, but then mainly fell to translations of the much broader compilation of Steno's works translated by Kardel and Maquet, ${ }^{1}$ all of which were approached in several ways. First, all indications, whether in the text or diagrams, of time, motion, and process observed or deduced from natural solids, were noted with particular

\footnotetext{
${ }^{31}$ S. J. Gould, S.J. in ref. 6.

${ }^{32}$ N. Desmarest in ref. 3.

${ }^{33}$ J. M. Hansen, On the origin of natural history: Steno's modern, but forgotten philosophy of science, in ref. 8 (Rosenberg), p. 159-178.

${ }^{34}$ T. Yamada, Kircher and Steno on the "geocosm", with reassessment of the role of Gassendi's works, in The origins of geology in Italy (Eds. G. B. Vai, W. G. E. Caldwell), Geological Society of America Special Papers, 2006, 411, p. 65-80.

${ }^{35}$ W. C. Parcell, Signs and symbols in Kircher's Mundus Subterraneus, in ref. 7 (Rosenberg), p. 63-74; C. J. Schneer, Steno on crystals and the corpuscular hypothesis, dissertations on Steno as geologist. Acta Historica Naturalium et Medicinalium, 1971, 34, p. 293-307.

${ }^{36}$ R. Rappaport, in ref. 10, p. 202.

${ }^{37} \mathrm{~J}$. G. Winter, The prodromus of Nicolaus Steno's dissertation concerning a solid body enclosed by process of nature within a solid. University of Michigan studies: Humanistic series, Macmillan, 1916, 115 pp.
}

attention to Steno's descriptions of minerals and incrustations in the Prodromus. The visual-cognition term 'feature' (see definition below) was then used to subdivide Steno's descriptions of temporal phenomena into classes according to chronology, process, and underlying material properties causing continuity, or disruption, of either or both chemistry and geometric orientation (Table 1). The sources of translated Steno quotes in Table 1 regarding Minerals and Strata occur in the main body of text, whereas the remainder are as follows for Fossils ${ }^{38}$ and Incrustations. ${ }^{39}$ Note that the $S_{5}$ class descriptor is based on a translation from Hansen (2009) in Ref. 8. Detailed class descriptions with relevant translations of Steno are presented alongside modern microscopy results for the $\mathrm{U}-\mathrm{Pb}$ geochronology of the mineral zircon. All microscopy was performed by the author's research group and collaborators using previously described electron beam techniques ${ }^{40}$ at the University of Western Ontario or using previously described atomic imaging techniques ${ }^{41,42}$ at the Canadian Centre for Electron Microscopy, McMaster University.

\section{Terminology for Stenonian time features}

The term feature has been used here to generalize the different signs or visual patterns which Steno ascribed to the effects of time's passage during the production or alteration of solid materials. Steno's raw visual observations are mostly expressed as geometric surfaces, with the word 'surface' here used according to the mathematical definition; a generalization of all planes which may or may not have some amount of curvature. Steno's geometric descriptions of surfaces in the Prodromus followed either Euclidean geometry or projective geometric representations of the Platonic solids in the tradition of Pierro, Kepler and Dürer ${ }^{43}$ and his single plate of diagrams ${ }^{44}$ combines these approaches. Notably,

\footnotetext{
${ }^{38} \mathrm{~N}$. Stensen, in ref. 1 (K\&M), p. 647-648.

${ }^{39} \mathrm{~N}$. Stensen, in ref. 1 (K\&M), p. 630.

${ }^{40}$ D. E. Moser, C. L. Cupelli, I. R. Barker, R. M. Flowers, J. R. Bowman, J. Wooden, J. R. Hart, New zircon shock phenomena and their use for dating and reconstruction of large impact structures revealed by electron nanobeam (EBSD, CL, EDS) and isotopic U-Pb and (U-Th)/He analysis of the Vredefort dome. Can. J. Earth Sci., 2011, 48, p. 117-139.

${ }^{41}$ J. R. Darling et al., Variable microstructural response of baddeleyite to shock metamorphism in young basaltic shergottite NWA 5298 and improved U-Pb dating of Solar System events. Earth Planet. Sci. Lett., 2016, 444, p. 1-12.

${ }^{42}$ G. A. Arcuri, D. E. Moser, D. A. Reinhard, D. Larson, B. Langelier, Impact-triggered nanoscale $\mathrm{Pb}$ clustering and $\mathrm{Pb}$ loss domains in Archean zircon. Contributions to Mineralogy and Petrology, 2020, 175, p. 59, 1-13.

${ }^{43}$ C. J. Schneer, in ref. 35.

${ }^{44}$ N. Stensen, in ref. 1 (K\&M), p. 658.
} 
and, perhaps unique for his time, are his two-dimensional projections and juxtaposition of three-dimensional geologic entities, such as sedimentary strata and growth layers within crystals, into a Euclidean plane which contains either the downward vector of Earth's gravity or the principal (central) axis of crystal growth. Steno does not refer to most of these features in formal geometric terms but as nouns with embedded actions. He does not, for instance, refer in Latin to a sedimentary deposit as a planum (plane), but as a stratum- the past participle of sternere "to spread out". Action, motion, and thus time, thereby become embedded meanings in his descriptor of a planar, natural feature.

Some have referred to parts of Steno's drawings as "structures", particularly the ruptured strata in his cross-sections of Tuscany; ${ }^{45}$ however, this term derives from structus, the past participle of struere "to pile,... assemble", whereas, at mineral grain or crystal lattice scales, these features are more accurately described by voids or a breakdown of order. As discussed below, Steno's methods are primarily visual, and consequently the visual term 'feature' is adapted here to encompass true structures and other types of recognizable material changes in solids. A 'feature', when used in regard to material objects, is defined in English as "some part which arrests the attention by its conspicuousness". ${ }^{46}$ Time is implicit in this definition - not in regard to the passage of time during production of the object but of time elapsing during the act of its observation during which the mind's attention is arrested. This process of observation will be discussed later in the context of Steno's methodology.

\section{RESULTS}

Upon consideration of Steno's observations of all natural solids, five classes of Stenonian time features signifying production or modification can be described, along with a brief mention of a sixth 'origin' class (Table 1). The first two classes of Stenonian time features can be considered as one or more Euclidean planes in that they, at length scales of observation typical in geology, are surfaces with zero curvature at any point. For Steno's "crystals" the planes in his diagrams are twodimensional projections of symmetrically-related set of crystal facets analogous to sedimentary strata (Fig. 1). Together they are the primary features of production and establish the reference features for discriminating

\footnotetext{
${ }^{45} \mathrm{~J}$. M. Hansen in ref. 33.

46 "feature, n." OED Online, Oxford University Press, December 2020, www.oed.com/view/Entry/68848.
}

later, modifying processes and events. The other three feature classes represent, at some scale, disruptions in continuity; what Steno described in the case of tilted strata as "obvious inequalities" 47 of angle with respect to the horizon and the gravitational field. At the atomic level in minerals, such discontinuities fall into two broad groups: discontinuity in chemistry, while maintaining crystalline order, and discontinuity due to a breaking or re-orienting of atomic bonds without necessarily changing the chemical composition. Each class is denoted with "S" for Steno and a subscript identifying the class number, and is described along with comparable features in zircon crystals.

a) $S_{0}, S_{1}$ Features representing growth, hiatus, environmental change

With regard to the beginning of the formation of a solid, Steno acknowledges that such a place must exist but would not speculate further. For minerals he stated that: "There may still be doubt about the place in which the first crystal begins, whether it be between fluid and fluid or between fluid and solid or in fact in a fluid by itself" ${ }^{\prime 8}$ and strata are described only as being preceded by a global fluid. Nevertheless Steno acknowledges the existence of a beginning point and it is represented in this scheme as $S_{0}$, the first point of production which, for minerals, is taken as the geometric centre of zoning (Fig. 1). From there he recognized, in different places in his writings on solids, subclasses of $S_{1}$ features to which he attributed vectors, pauses, and environmental changes during production.

\section{Vectors and nature of growth processes}

Steno's view of mineral growth shared some similarities with sedimentary strata but with important differences in the kinetics of growth. In both solids he saw that; "The growth of all solids is from fluids" and that a body "grows by addition of new particles" ${ }^{49}$ Hearkening to his choice of the term stratum for sedimentary layers, Steno indicates that "new crystalline material, added to the crystal, is spread out over a plane"50 with the important difference that "buoyancy or gravity are not involved", ${ }^{51}$ and crystal growth is instead driven by "the subtle fluid permeating all matter" 52 . Thus gravity controls sedimentation in a single, vertical field, whereas particle addition in another field causes crystals to grow

\footnotetext{
${ }^{47}$ N. Stensen, in ref. 1 (K\&M), p. 653.

${ }^{48} \mathrm{~N}$. Stensen, in ref. 1 (K\&M), p. 639.

${ }^{49} \mathrm{~N}$. Stensen, in ref. 1 (K\&M), p. 630.

${ }^{50}$ N. Stensen, in ref. 1 (K\&M), p. 642.

${ }^{51}$ N. Stensen, in ref. 1 (K\&M), p. 634.

${ }^{52}$ N. Stensen, in ref. 1 (K\&M), p. 631.
} 
Table 1. A classification scheme for Stenonian time features in solids (top row) based on representative Steno descriptions symbolized as; "quotations from Steno (transl.)", 'author's condensation of translated text', and [modern terminology]. Arrows represent cases where features in strata are now known to have analogous mineral features. ${ }^{*}$ Far left column identifies the quality of the continuity change across each feature relative to its surroundings as; chemical (C), geometric orientation (O) or a combination of either or both (C $\| \mathrm{O})$. See Methods for sources of translated Steno quotations.

\begin{tabular}{|c|c|c|c|c|c|}
\hline & & $\begin{array}{l}\text { "Angular solids" } \\
\text { [Minerals] }\end{array}$ & "Strata" & [Fossil] & $\begin{array}{l}\text { "Incrustations" } \\
\text { [Concretions] }\end{array}$ \\
\hline * & $\underline{\text { Stenonian time feature class }}$ & & & & \\
\hline C & $\mathrm{S}_{5}$; intra-solid diffusion & $\begin{array}{l}\text { smallest particles in } \\
\text { "inner revolt" }\end{array}$ & [metamorphism] & & \\
\hline $\mathrm{o}$ & $\begin{array}{l}\mathrm{S}_{4} \text {; deformation (brittle, } \\
\text { rapid) }\end{array}$ & $<-$ & $\begin{array}{c}\text { "shattering" causing } \\
\text { "obvious inequalities" } \\
\text { in angles }\end{array}$ & & \\
\hline $\mathrm{o}$ & $\mathrm{S}_{4}$; deformation (plastic, slow) & $<-$ & $\begin{array}{l}\text { "subsidence", } \\
\text { "twisting into curves" }\end{array}$ & & \\
\hline $\mathrm{C} \| \mathrm{O}$ & $\mathrm{S}_{3}$; mechanical erosion & "fractured sides" & $\begin{array}{c}\text { [erosional } \\
\text { unconformity] }\end{array}$ & & \\
\hline $\mathrm{C} \| \mathrm{O}$ & $\mathrm{S}_{3}$; chemical erosion & $\begin{array}{l}\text { dissolution "cavity" } \\
\text { leaving "lamellae" }\end{array}$ & $\begin{array}{c}\text { [chemical } \\
\text { unconformity] }\end{array}$ & $\begin{array}{c}\text { 'shell partly destroyed, } \\
\text { eaten away' }\end{array}$ & \\
\hline $\mathrm{C} \| \mathrm{O}$ & $\mathrm{S}_{2}$; end of production & $\begin{array}{l}\text { surface of "angular } \\
\text { solid", form related to } \\
\text { 'constancy of angles' }\end{array}$ & $\begin{array}{l}\text { "upper surface } \\
\text { is parallel to the } \\
\text { horizon" final form } \\
\text { related to gravity }\end{array}$ & $\begin{array}{l}\text { "outer edge of the } \\
\text { animal" }\end{array}$ & $\begin{array}{l}\text { 'outer surface of } \\
\text { concretion' controlled } \\
\text { by roughness of place }\end{array}$ \\
\hline c & $\mathrm{S}_{1}$; hiatus in production & $\begin{array}{l}\text { "if...crystal contained } \\
\text { by crystal" then } \\
\text { "contained bodies } \\
\text { already hard" }\end{array}$ & $\begin{array}{l}\text { 'fluid recession, } \\
\text { sediment hardening, } \\
\text { and fluid return' }\end{array}$ & & \\
\hline C & $\begin{array}{l}\mathrm{S}_{1 ;} \text { growth and environmental } \\
\text { change during growth }\end{array}$ & $\begin{array}{l}\text { "crystal grows while } \\
\text { new crystalline } \\
\text { material is added to } \\
\text { the already formed } \\
\text { crystal" colour zoning } \\
\text { due to "ingress of new } \\
\text { material" }\end{array}$ & $\begin{array}{l}\text { strata differences due } \\
\text { to "different kinds of } \\
\text { fluid from different } \\
\text { places through that } \\
\text { spot at different } \\
\text { times" }\end{array}$ & $\begin{array}{c}\text { 'imprint on each } \\
\text { margin of the } \\
\text { testulae' }\end{array}$ & \\
\hline c & $\mathrm{S}_{1}$; growth domain & $\begin{array}{l}\text { crystal layer created } \\
\text { by "addition of } \\
\text { new particles in } \\
\text { succession" }\end{array}$ & "stratum" & $\begin{array}{c}\text { "testulae" } \\
\text { mollusc shells }\end{array}$ & $\begin{array}{c}\text { "fluid directs material } \\
\text { to the solid on all } \\
\text { sides" }\end{array}$ \\
\hline & $\mathrm{S}_{0}$; start of production & $\begin{array}{l}\text { "doubt about the } \\
\text { place in which first } \\
\text { hardening of the } \\
\text { crystal begins" } \\
\text { [nucleation] }\end{array}$ & $\begin{array}{c}\text { "Creation from a } \\
\text { fluid that covered all } \\
\text { things" }\end{array}$ & $\begin{array}{l}\text { point of nucleation } \\
\text { 'seed' }\end{array}$ & \\
\hline
\end{tabular}

along several, mathematically related directions. Steno analogized crystal growth with particles aligning like iron filings in a magnetic field such that "both the number and length of the sides are changed in various ways without the angles being changed." ${ }^{3}$. Flow in the mineral's parent liquid did not alter the direction of the field driving crystallization in that "the movement of crystal-

${ }^{53}$ N. Stensen, in ref. 1 (K\&M), p. 642, also ref. 41. line material [...] depends on the movement of the tenuous fluid that flows from the already formed crystal". ${ }^{54}$

\section{Successional growth}

Among the most important spatiotemporal deductions by Steno was that of the successional growth of lay-

${ }^{54}$ N. Stensen, in ref. 1 (K\&M), p. 642. 


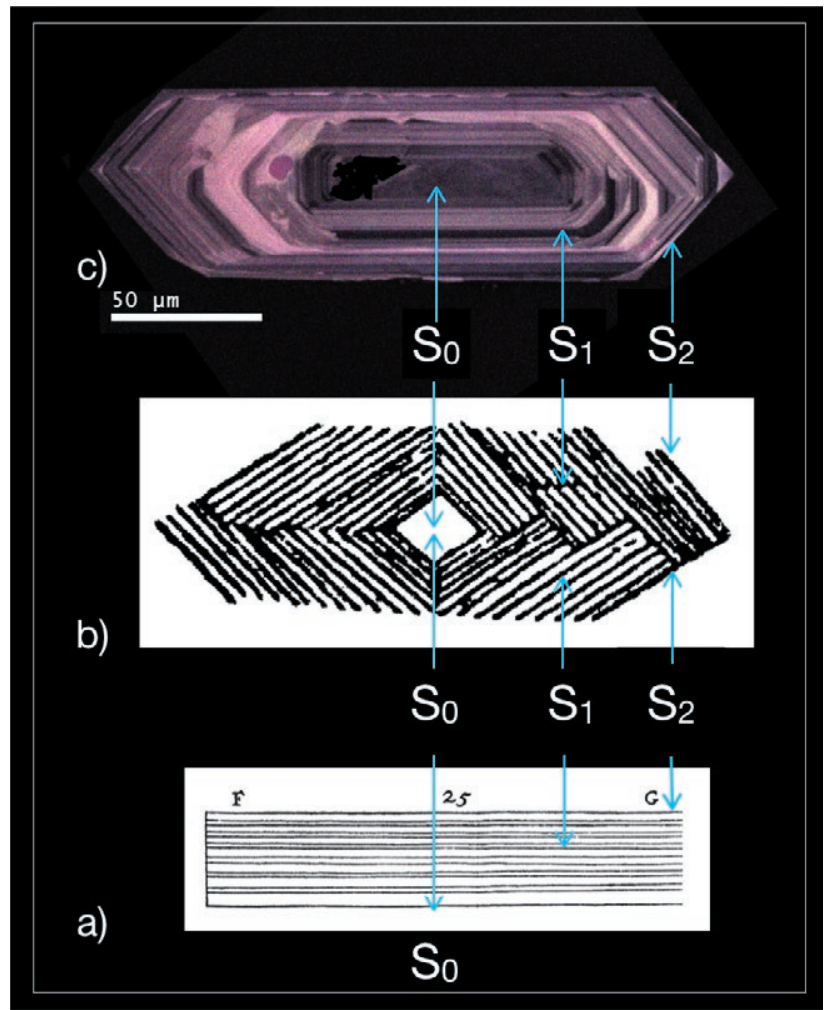

Figure 1. Stenonian time features of production $\left(S_{0}, S_{1}, S_{2}\right.$, see text) from Plate 1 of the Prodromus ${ }^{1}$ showing a) undeformed strata (kmscale), b) growth zones in sectioned quartz (cm-scale) and c) SEMCL image of a polished section through a zircon microcrystal (note scale bar 5 micrometre scale bar). ${ }^{1} \mathrm{~N}$. Stensen, in ref. 1 (K\&M), p. 658.

ers in solids. For minerals he noted that "crystal growth was not vegetative" 55 as in herbaceous plants. His argument against the vegetative mineral growth hypothesis can be traced to his discussion of the growth layers within the class of solids he termed "incrustations" (i.e., agates, geodes). He describes the "differences in layers" in these solids with the important time descriptor of relative age; "succession". ${ }^{56} \mathrm{He}$ recognized the curviplanar geometry and extension of the concentric layers in these "stones composed of layers the two surfaces of which are indeed parallel but are not extended in the same plane". He then compared these to the concentric, curviplanar growth layers in non-herbaceous woody plants "where they show the round veins of a tree cut transversely". ${ }^{57}$ Steno contrasts these processes for mineralized bodies with those giving rise to strata, stating that:

\footnotetext{
${ }^{55} \mathrm{~N}$. Stensen, in ref. 1 (K\&M), p. 640.

${ }^{56} \mathrm{~N}$. Stensen, in ref. 1 (K\&M), p. 634.

${ }^{57} \mathrm{~N}$. Stensen, in ref. 1 (K\&M), p. 633.
}

Additions [of particles] made directly to a solid from an external fluid sometimes fall to the bottom because of their own weight, as in the case of sediments; sometimes the additions are made from a penetrating fluid that directs material to the solid on all sides, as in the case of incrustations. $^{58}$

The outward growth of minerals is now universally recognized and utilized in the fields of petrology and mineralogy in which rocks and minerals are examined in polished, transparent sections, and likewise in zircon geochronology where SEM-CL microscopy is used to reveal $S_{1}$, concentric growth banding. These represent changes in trace element chemistry inherited from the magma and are expressed as variations in luminescent intensity and/or colour (Fig 1). The orientation of the crystal lattice across the chemical zoning does not change such that banding marks discontinuities in chemistry within a zone of continuous crystal orientation.

\section{Time gap (hiatus) in growth}

"Stony strata are found between earthy strata" due to a "fluid, having receded from the sediment that had been deposited, returned again when the upper crust had become hardened by the heat from the sun". ${ }^{59}$ Beyond outward growth, Steno recognized that both the conditions and rate of growth can vary during the production of natural solids. Drawing on his writings on strata, he clearly envisions a scenario wherein either or both a time gap and changes in the formative environment results in variations in visual properties across a set of layers. In his second proposition he states, "if at any time a crystal is partly enclosed by a crystal, a marcasite by a marcasite, then at a time when these contained bodies were already hard, part of the containing body was still fluid". ${ }^{60}$ A corresponding recognition of hiatus in sedimentation was also noted as possible (above). We now know that concentric, apparently continuous, zoning sequences within zircon grains released from a single volcanic eruption lasting days can, in some cases, represent age differences of hundreds of thousands of years; their $S_{1}$ features a product of halting outward growth over this period. The crystal shown in Fig.1 is representative of those from a Cretaceous ash layer, now exposed in the Canadian Rocky Mountains. Absolute dating of such grains indicates that the zoning represents up to sev-

\footnotetext{
${ }^{58}$ N. Stensen, in ref. 1 (K\&M), p. 630

${ }^{59}$ N. Stensen, in ref. 1 (K\&M), p. 635

${ }^{60}$ N. Stensen, in ref. 1 (K\&M), p. 629.
} 
eral hundred thousands of years of crystallization prior to eruption ${ }^{61}$.

\section{Environmental change during growth}

Difference in layers at the same place can be produced either by the diversity of particles leaving the fluid in succession, as this fluid is gradually dissipated more and more, or by different fluids being conveyed there at different times: so it happens that sometimes the arrangement of layers is repeated in the same place, and often evident signs exist showing the ingress of new material. ${ }^{62}$

Steno was careful to distinguish "place" (i.e., the place or environment where a solid was produced) from the "location", or site of discovery of that solid, recognizing that "location does not explain production". ${ }^{63}$ In the case of strata, Steno also recognized that changes in the sedimentary section could reflect changes in sedimentary conditions and sources through time, and that stratal changes vertically result from "different kinds of fluid from different places through that spot at different times". Similarly for minerals, Steno understood that the place of production imbues solids with signatures of their native environments, such that "Rocks of different types, emitting different fluids, produce crystals of different colours" ${ }^{\prime \prime}$. Moreover, Steno realized that even in the place of production, an environment of crystallization can change during the growth such that "sometimes in the same crystal the parts first hardened are sometimes darker than those hardened last". ${ }^{65}$ We now know that igneous minerals commonly show internal compositional layering due to very local effects of growth-limiting elements among other factors such as surface energy, magma viscosity, and temperature, as is known for both quartz ${ }^{66}$ and zircon. ${ }^{67}$

\section{b) $S_{2}$ final form at end of production}

A second class of Stenonian time feature is defined as the exterior or upper surface of a solid at the completion of its growth in the place of production. For miner-

\footnotetext{
${ }^{61}$ I. R. Barker, D. E. Moser, S. Kamo, G. Plint, High-precision U-Pb zircon ID-TIMS dating of two regionally extensive bentonites: Cenomanian Stage, Western Canada Foreland Basin. Can. J. Earth Sci., 2011, 48, p. 543-556.

${ }^{62} \mathrm{~N}$. Stensen, in ref. 1 (K\&M), p. 634.

${ }^{63} \mathrm{~N}$. Stensen, in ref. 1 (K\&M), p. 628

${ }^{64} \mathrm{~N}$. Stensen, in ref. 1 (K\&M), p. 641.

${ }^{65} \mathrm{~N}$. Stensen, in ref. 1 (K\&M), p. 641.

${ }^{66}$ D. A. Wark, B. E. Watson, TitaniQ: a titanium-in-quartz geothermometer. Contributions to Mineralogy and Petrology, 2006, 152, p. 743-754.

${ }^{67}$ P. W. O. Hoskin, Patterns of chaos: Fractal statistics and the oscillatory chemistry of zircon. Geochimica et Cosmochimica Acta, 2000, 64, p. $1905-1923$
}

als crystallizing from a liquid, $\mathrm{S}_{2}$ is a polyhedral surface composed of Euclidean planes (crystal growth facets) the orientations of which follow Steno's law of angular constancy. Figure 2 illustrates Steno's method of projecting this three dimensional surface such that "all the 12 planes laid out in one plane" ${ }^{68}$ and neighbouring crystal facets connected by a shared vertex. He recognized it as a time marker implicitly in his use of it to infer order of crystal growth (above). It should be noted that Steno did not consider metamorphic minerals, i.e. crystals that grew while most of its surroundings were solid. The $\mathrm{S}_{2}$ surface of such grains reflects some combination of growth processes and surface energies among surrounding mineral phases ${ }^{69}$. In either case, the final, outer surface represents a discrete point along time's arrow. This is at once the simplest and perhaps most important time feature for Steno's interpretation of fossils as it occurs at the meeting place of an object with its surroundings (rock, air, etc.) at its present location (Table 1). The $\mathrm{S}_{2}$ feature class includes the uppermost surface of a stratum, the final form of an organism, or the outermost atomic layers of a crystal. This was the key time feature used to discriminate between an allocthonous (transported from elsewhere) vs. autochthonous (formed in situ) origin for Steno's fossils relative to their found location (i.e. Desmarest's Premier Principé). This feature is of central importance in the Prodromus and remains a key tool in the modern geochronologic interpretations of minerals such as zircon as to whether or not they are endogenic or exotic to their current setting.

\section{c) $S_{3}$ modifications of original form}

The $\mathrm{S}_{3}$ class of features, along with the other two remaining classes, share the characteristic of being surfaces marking discontinuities in one or both of chemical composition and crystallographic (atomic) orientation, with the change occurring over a length-scale much less than that of the relevant surfaces.

\section{$\mathrm{S}_{3}$ due to chemical erosion (dissolution)}

just as a crystal has formed from a fluid, so that same crystal can be dissolved in a fluid, provided one knows how to imitate nature's true solvent. ${ }^{70}$

Following on his basic statement that all solids grow from fluids, Steno concludes that the process can operate in reverse (above). It is plausible that Steno shows

\footnotetext{
${ }^{68}$ N. Stensen, in ref. 1 (K\&M), p. 659.

${ }^{69}$ R. Kretz, On the spatial distribution of crystals in rocks. Lithos, 1969, 2, p.39-69.

${ }^{70}$ N. Stensen, in ref. 1 (K\&M), p. 643.
} 


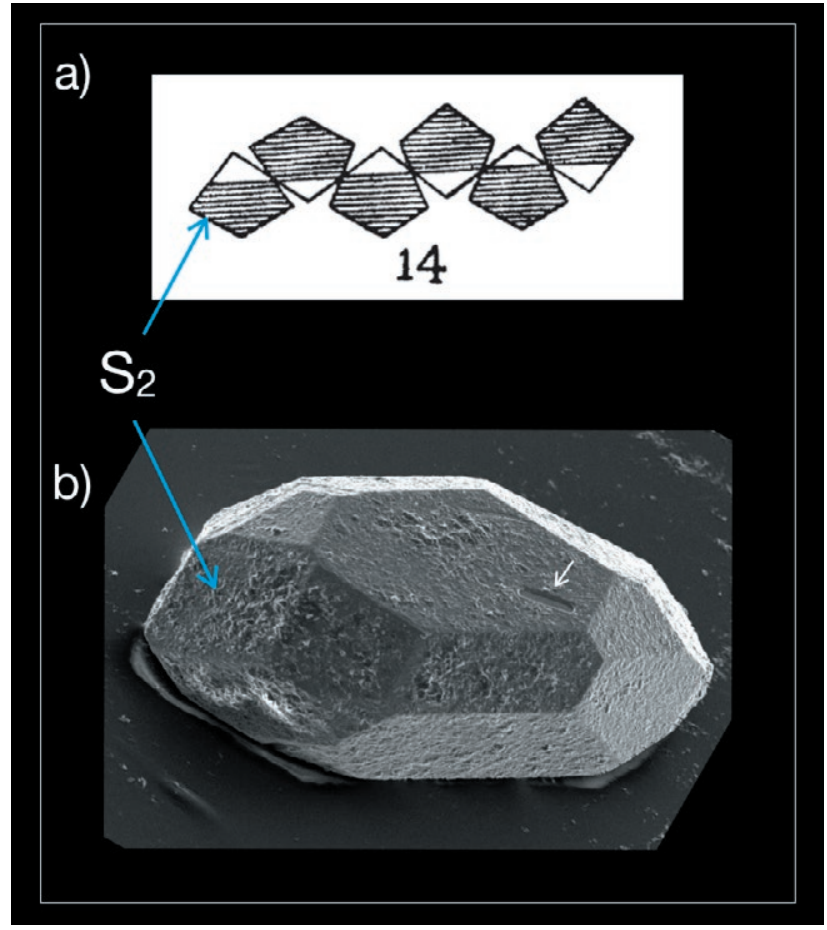

Figure 2. Two views of Steno's final surface of production $\left(S_{2}\right)$ in minerals; a) Steno's two dimensional representation of the external, Euclidean planes of an "iron" crystal (marcasite) b) An SEM image of a euhedral, igneous zircon crystal, same sample as in Figure 1c (grain length $=250$ micrometres). Note the mould of a smaller grain (white arrow), likely the mineral apatite, encountered during the last increment of growth before eruption.

the effects of dissolution in his Diagram 6 where he describes "that various cavities are left in the very middle of the crystal and various lamellae are formed." 71 (Fig. 3). This diagram could be interpreted to show a partly dissolved quartz crystal with lamellae of relict growth layers $\left(\mathrm{S}_{1}\right)$ from the originally continuous solid body. Alternatively, the lamellae could represent a face of relatively slow crystal growth frustrated due to surface kinetic effects. Regardless, it is clear that Steno anticipated dissolution during natural processes. Resorption surfaces similar to the forms in Steno's drawing were produced in zircon by Prof. Thomas Krogh in laboratory etching experiments ${ }^{72}$ and rounding of originally equant zircons due to metamorphic fluids in the crust is now widely documented. ${ }^{73}$ Often this stage of resorp-

\footnotetext{
${ }^{71}$ N. Stensen, in ref. 1 (K\&M), p. 646.

${ }^{72}$ D. W. Davis, I. Williams, T.E. Krogh, Historical development of zircon geochronology. Reviews in Mineralogy and Geochemistry, 2003, 53, p. $145-181$

${ }^{73}$ M. J. Kohn, N. M. Kelly, Petrology and geochronology of metamorphic zircon, in Microstructural geochronology: planetary records down to atom scale (Eds. D. E. Moser, F. Corfu, J. R. Darling, S. M. Reddy, K. T.
}

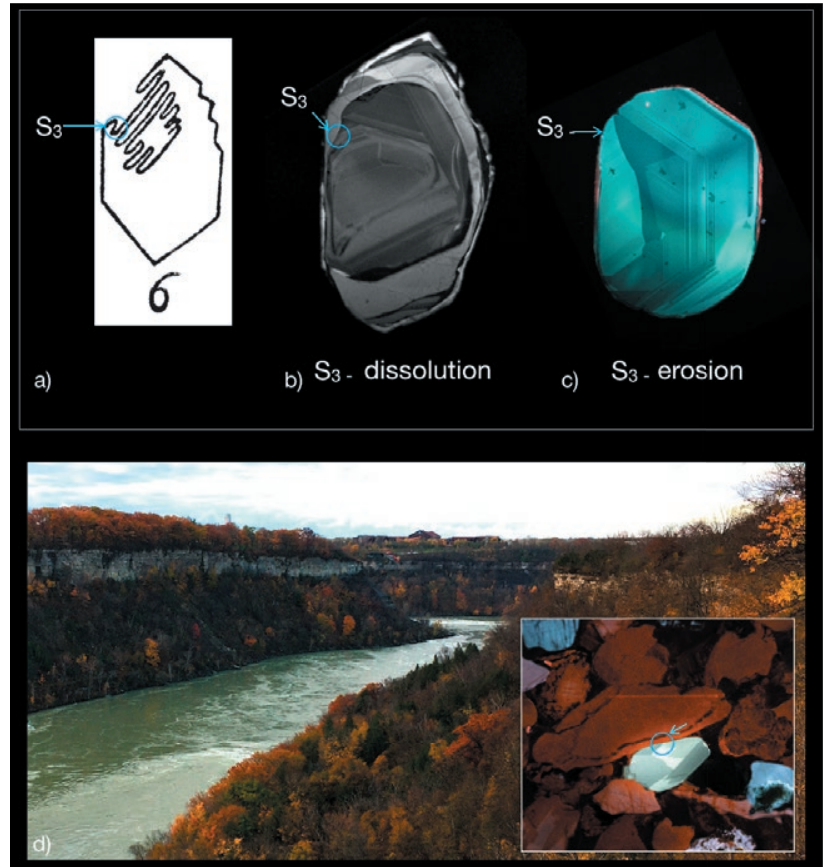

Figure 3. Features of modification: a) Steno's quartz crystal and a surface of $\mathrm{S}_{3}$ chemical dissolution. Zircon SEM-CL images showing b) 4.02 billion year $S_{1}$ growth features truncated by a $S_{3}$ dissolution (metamorphic) surface, c) a zircon from beach sand with external $\mathrm{S}_{3}$ surface of mechanical erosion. d) Southward view from Canada of the Niagara River Gorge and the type locality for the Silurian Whirlpool sandstone; Inset, SEM-CL image of rounded zircon sand grain among quartz grains (red), Whirlpool sandstone. All zircon grain lengths $\sim 300$ micrometres.

tion is followed by renewed zircon growth continuous in lattice orientation (i.e. epitaxial growth), but different in chemical composition (Fig 3). This creates a feature visually akin to an angular unconformity in strata, as shown in a 4.02 billion year old zircon from Earth's oldest known rock (Fig. 3). ${ }^{74}$

\section{$S_{3}$ due to mechanical erosion}

"nor have I ever seen a crystal whose still unbroken surfaces have the smoothness that the fractured sides of the same crystal show after it has been broken apart." 75

Steno was clear that a solid body could form in one place and move to another unrelated to its genesis: "since the earth bestows location at least in part to all

Tait), Hoboken, NJ, Wiley, 2017, p. 35-61.

${ }^{74}$ J. R. Reimink, T. Chacko, R. A. Stern, L. M. Heaman, Earth's earliest evolved crust generated in an Iceland-like setting. Nature Geoscience, 2017, 7 , p. 529-533.

${ }^{75}$ N. Stensen, in ref. 1 (K\&M), p. 642. 
the things of the earth, the location by itself does not explain the production of a body". ${ }^{76} \mathrm{He}$ recognized that "Mountains can be destroyed", 77 that cavities can be filled with "earthy material eroded from higher places by the continuous rainfall", ${ }^{78}$ and that the particles in sediments sink under their own weight even if "conveyed there from elsewhere". ${ }^{79}$ In his series of strata cross-sections he notes "hills and valleys produced there by the destruction of the upper sandy strata" ${ }^{80}$ These clues to motion and erosion on the outer surface of the Earth were also noted for crystals ${ }^{81}$ and the incrustations:

Incrustations are observed to be rough like ordinary stones on the outer surface, since the outer surface of the outer layer depicts the roughness of the place; in torrents, however, incrustations of this kind are often found away from the place of production because the material of the place has been scattered by the bursting of the strata. ${ }^{82}$

Steno recognized the difference between growth faces and those modified by breakage (above) and this is a second type of intersection relationship with the original outer form or surface $\left(\mathrm{S}_{2}\right)$; one that is due not to dissolution of particles in a surrounding fluid but to mechanical abrasion or breakage during transport which modifies the original form causing an interruption in the continuity of the internal features when viewed in section (Fig. 3). Zircon grains are extremely resistant to chemical and mechanical breakdown, and the oldest known pieces of the earth are fine, sand-sized grains of zircon in much younger, though still ancient, sediments. ${ }^{83}$

\section{e) $S_{4}$ features due to episodes of deformation}

The earth's strata can alter position in two ways. The first way is the violent upheaval of strata, whether this be due mainly to a sudden flare of subterranean gases or to a violent explosion of air caused by other great subsidence nearby. This upward thrust of strata is followed by a dispersal of earthy material as dust and the shattering of rock material into pebbles and rough fragments. The second way is the spontaneous slipping or subsidence of the upper strata after they have begun to crack because of the withdrawal of the underlying substance or foundation; [...] While some remain parallel to the horizontal, others become vertical; many make oblique angles with the horizon and not a

\footnotetext{
${ }^{76}$ N. Stensen, in ref. 1 (K\&M), p. 628.

${ }^{77}$ N. Stensen, in ref. 1 (K\&M), p. 637.

${ }^{78}$ N. Stensen, in ref. $1(\mathrm{~K} \& M)$, p. 656.

${ }^{79} \mathrm{~N}$. Stensen, in ref. 1 (K\&M), p. 634

${ }^{80} \mathrm{~N}$. Stensen, in ref. 1 (K\&M), p. 660.

${ }^{81} \mathrm{~N}$. Stensen, in ref. 1 (K\&M), p. 640

${ }^{82}$ N. Stensen, in ref. 1 (K\&M), p. 633.

${ }^{83} \mathrm{~J}$. W. Valley et al., in ref. 21.
}

few are twisted into curves because of the tenacity of their material. ${ }^{84}$

Whereas Steno described deformation of the exterior of minerals, he did not remark on internal effects; so, for this class of time feature, we look to his insights gained from sedimentary strata and compare these to modern studies of zircon. As seen in the above quote Steno made some highly astute observations, recognizing two styles of deformation of strata and their respective geometric and material consequences. Steno was accurately describing the range of mechanical responses to different rates of deformation. He did not depict the first style in the Prodromus; that of violent, or very rapid, deformation but it is likely he was referring to the consequences of volcanic activity. The most extreme strain rate events now known to affect planetary crusts occur at the deepest levels of tectonic collision zones, and, at the most extreme end of the spectrum, within large meteorite impact craters as illustrated here with terrestrial and lunar zircon (Fig. 4).

\section{$S_{4}$ due to rapid deformation}

Zircon is one of the minerals most resistant to destruction by impact-related shock metamorphism, yet grains develop long-lasting and unique deformation features ${ }^{85}$ Fracturing and crystal distortions occur in microseconds and often under extreme, short-lived temperatures of up to a few thousand degrees Celsius. Disordered mineral glasses, instead of secondary minerals, can fill crystallographic fractures, a material difference alluded to by Steno: "the main cause of variation by which crystal differs from glass not only in refraction but also in other properties, since, in glass, no parts of the dissolving fluid are present, as they have driven forth by the violence of fire" ${ }^{86}$ This deformation style of $\mathrm{S}_{4}$ features has been recognized at the Vredefort crater in South Africa, offsetting $S_{1}$ growth zoning and $S_{2}$ surface of production (Fig. 4). We see a similar sequence in the features of $>4$ billion year old lunar zircons, including those recovered by the U.S. Apollo 17 mission near Steno Crater $^{87}$ (Fig. 4). In both cases, the zircon lattice

\footnotetext{
${ }^{84}$ N. Stensen, in ref. 1 (K\&M), p. 636.

${ }^{85}$ D. E. Moser, C. L. Cupelli, I. R. Barker, R. M. Flowers, J. R. Bowman, J. Wooden, J. R. Hart. New zircon shock phenomena and their use for dating and reconstruction of large impact structures revealed by electron nanobeam (EBSD, CL, EDS) and isotopic U-Pb and (U-Th)/He analysis of the Vredefort dome. Can. J. Earth Sci., 2011, 48, p. 117-139. ${ }^{86}$ N. Stensen, in ref. 1 (K\&M), p. 643.

${ }^{87}$ B. Zhang et al., Imbrium Age for Zircons in Apollo 17 South Massif Impact Melt Breccia 73155. JGR Planets, 2019, 124, p. 3205-3218
} 


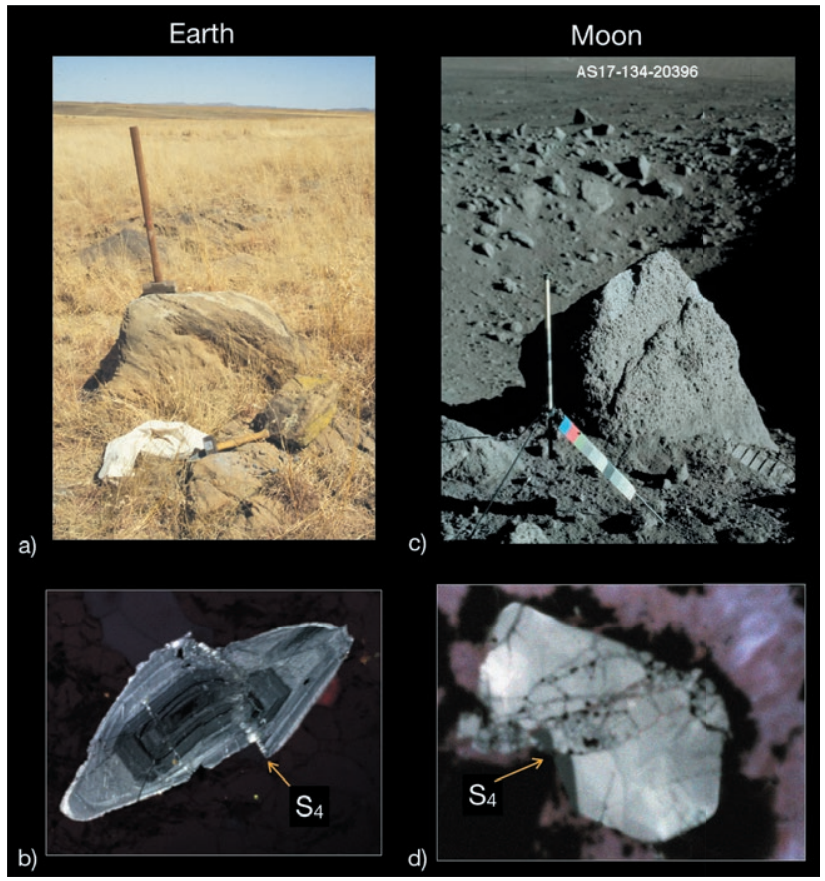

Figure 4. Examples of violent deformation features $\left(\mathrm{S}_{4}\right)$ on Earth and the Moon: a) a boulder of Archean ( $\sim 3$ billion year old) crust near the center of the $\sim 250 \mathrm{~km}$ wide, 2.020 billion year old Vredefort impact structure of South Africa. b): SEM-CL image of a zircon crystal from this region c) boulder at the edge of Steno Crater ( Apollo 17), d) SEM-CL image of a $>4$ billion year old zircon from near site shown in c).

between fracture sets has been bent by several degrees during shock deformation, a mechanical response in line with Steno's observation for strata which sometimes respond plastically to be "twisted into curves" because of their "tenacity" (above).

\section{$S_{4}$ tectonic fracturing and mineral-filled veins}

Steno also recognized a style of deformation features such that some strata crack in a brittle fashion to allow fluid pathways for new mineral precipitates. An example of this sequence of $S_{4}$ features superimposed on generations of growth features $\left(S_{1 a}, S_{1 b}\right)$ is illustrated here in one of the oldest known fragments of the Earth; a zircon grain from the Archean Jack Hills quartzite from the Yilgarn craton of Western Australia (Fig. 5a). The age, chemistry and microstructure of this grain has been described in detail elsewhere. ${ }^{88}$ The central domain (core) has a U-Pb age of 4.38 billion years - a time when the mass of the Moon had already been separated

${ }^{88} \mathrm{~J}$. W. Valley et al., in ref. 21. from the proto-Earth and the first water appeared, ${ }^{89}$ the latter reminiscent of Steno's first fluids. The first set of growth features $\left(S_{1 a}\right)$ formed during precipitation from a silica-rich magma in Earth's early continental crust. At modern, average rates of tectonic drift, it is plausible that over the last 4 billion years this core domain has circumnavigated the Earth several times as microscopic continental cargo on a number of early crustal domains. Roughly 3.4 billion years ago, the grain experienced chemical resorption and/or mechanical abrasion which removed $\mathrm{S}_{2}$ and produced a discontinuity surface, $\mathrm{S}_{3}$, over which grew a new, metamorphic domain with chemical layering $\left(\mathrm{S}_{1 \mathrm{~b}}\right)$ discordant to the older core. A tectonic deformation produced $S_{4}$ fractures, which reoriented the lattice and its $S_{1 a}, S_{1 b}$ and $S_{3}$ features, prior to their being filled with a combination of new zircon, quartz, and grains of the rare earth phosphate xenotime, the latter as young as 0.8 billion years ago ${ }^{90}$ (Fig. 5). The mineralogy of the micro-veins, and their younger, intersectional age relationship, are directly in line with Steno's observations of the deformation, veining and growth of secondary minerals. ${ }^{91}$ The sequence of production (growth), erosion, deformation, and resumption of growth experienced by this early Earth zircon resulted in a geometric arrangement of features that is very similar to that which Steno described for the crustal strata of Tuscany, illustrating the scale-invariance of Stenonian geochronology (Fig. 5).

\section{$S_{4}$ Deformation and renewed production sequence at atom- ic scales}

Stenonian cycles of production and modification can also be seen at the atomic level with electron microscopy at the length scale of Steno's then "imperceptible particles", ${ }^{92}$ as illustrated here in a 200 million year old igneous Mars rock that came to Earth as a meteorite (NWA 5298) $\sim 11$ million years ago ${ }^{93}$ (Fig. 6). The cycle of rapid shock-wave deformation and heating, which such shergottite meteorites generally experience as they are ejected to space following an impact event, leaves a record of mm-scale pockets of melting and glass for-

\footnotetext{
${ }^{89}$ SA Wilde, JW Valley, WH Peck, CM Graham, Evidence from detrital zircons for the existence of continental crust and oceans on the Earth 4.4 Gyr ago. Nature, 2001, 409, p. 175-178.

${ }^{90}$ Rasmussen B. et al., Metamorphic replacement of mineral inclusions in detrital zircon from Jack Hills, Australia: Implications for the Hadean Earth. Geology, 2011, 39, p. 1143-1146.

${ }^{91} \mathrm{~N}$. Stensen, in ref. $1(\mathrm{~K} \& \mathrm{M})$, pp. 629.

${ }^{92} \mathrm{~N}$. Stensen, in ref. 1 (K\&M), pp. 626.

${ }^{93}$ Moser, D. E. et al., Solving the Martian meteorite age conundrum using micro-baddeleyite and launch-generated zircon. Nature, 2013, 499 , p. $454-457$.
} 


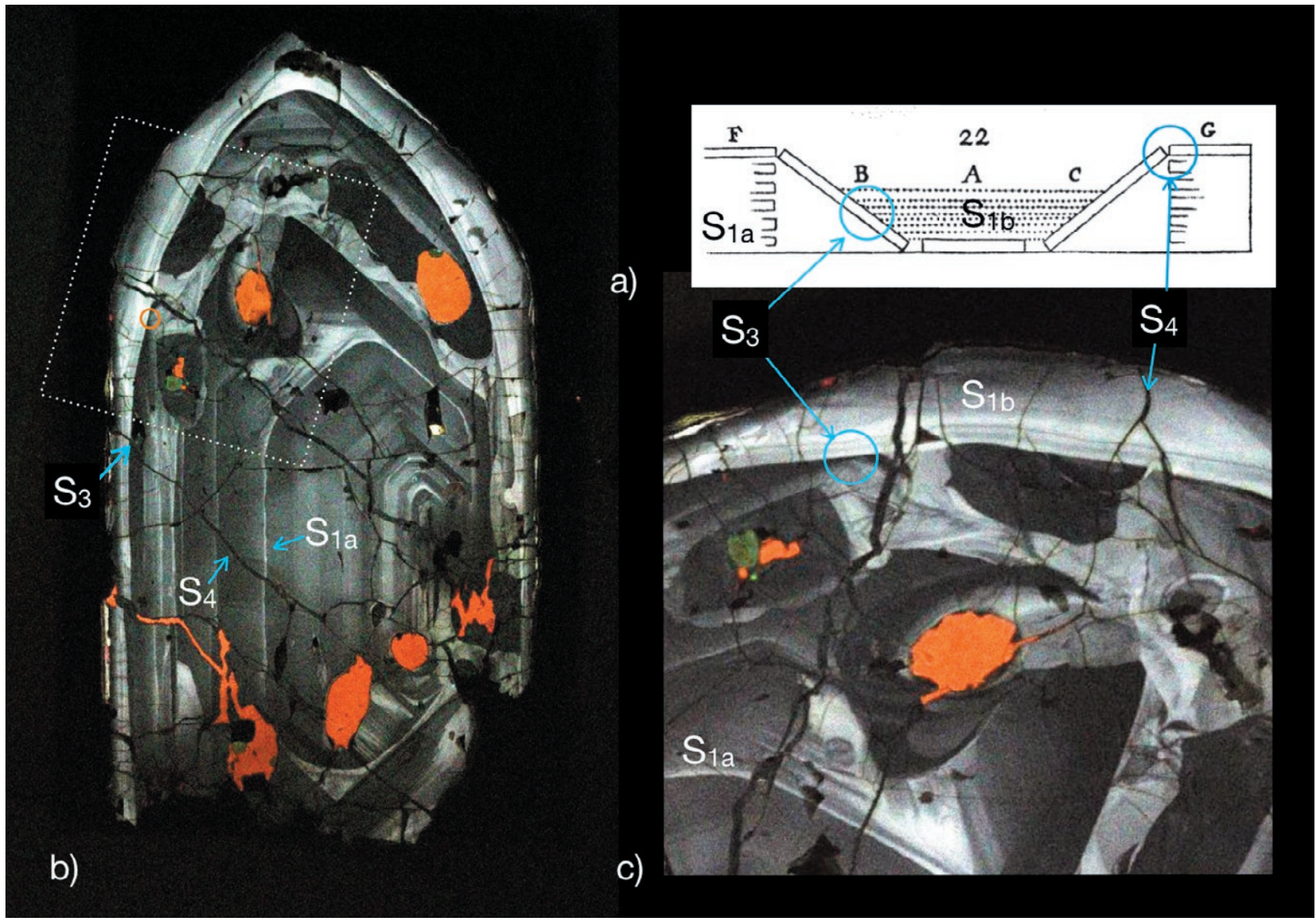

Figure 5. Cyclic growth and deformation; a) Steno's depiction of Tuscan strata (see text for description of annotations), b) SEM -CL image of one of Earth's oldest known mineral grains, zircon with a 4.38 billion year old core. The 3.6 billion year sequence of growth, erosion, deformation and renewed growth features can be seen in higher magnification view of white dotted box, enlarged in c).

mation as well as a suite of microscopic $\mathrm{S}_{4}$ deformation features within the regular atomic layering of igneous crystals. The heating also triggers short-lived chemical reactions and local growth of minerals, including zircon, during cooling en route to space. ${ }^{94}$ The resulting continuous and discontinuous patterns among the atomic lattice layers, revealed with electron microscopy, are analogous to the those in strata in Steno's sketches of Tuscan geology (Fig. 6). We can see in Figure 6 that primary atomic layering $\left(\mathrm{S}_{1 \mathrm{a}}\right)$ in the Mars mineral baddeleyite $\left(\mathrm{ZrO}_{2}\right)$, has been re-oriented and disordered across $\mathrm{S}_{4}$ surfaces of deformation. A boundary of chemical reaction $\left(\mathrm{S}_{3}\right)$ separates the deformed baddeleyite features from younger, atomic layers of undeformed zircon $\left(\mathrm{S}_{1 \mathrm{~b}}\right)$ at the start of its journey to Earth (Fig 6). This atomscale Stenonian geochronology, when paired with absolute geochronology methods, allows for back-stripping

94 ibid. and dating of a microscopic deformation and chemical erosion sequence developed on a path between planets. ${ }^{95}$

f) $S_{5}$ Chemical diffusion, chronostructures, and Steno's known unknown process

Thus I do not determine whether particles of a natural substance can or cannot undergo change, as its shape can, whether there are or are not minute empty spaces whether in those particles, in addition to the ability to occupy space and the property of hardness, there may not be something else unknown to us; for these statements are not widely accepted, and it is a feeble argument to deny that there is anything else in a certain thing because I do not observe anything else in it. ${ }^{96}$

${ }^{95}$ ibid.

${ }^{96}$ N. Stensen, in ref. 1 (K\&M), p. 626. 


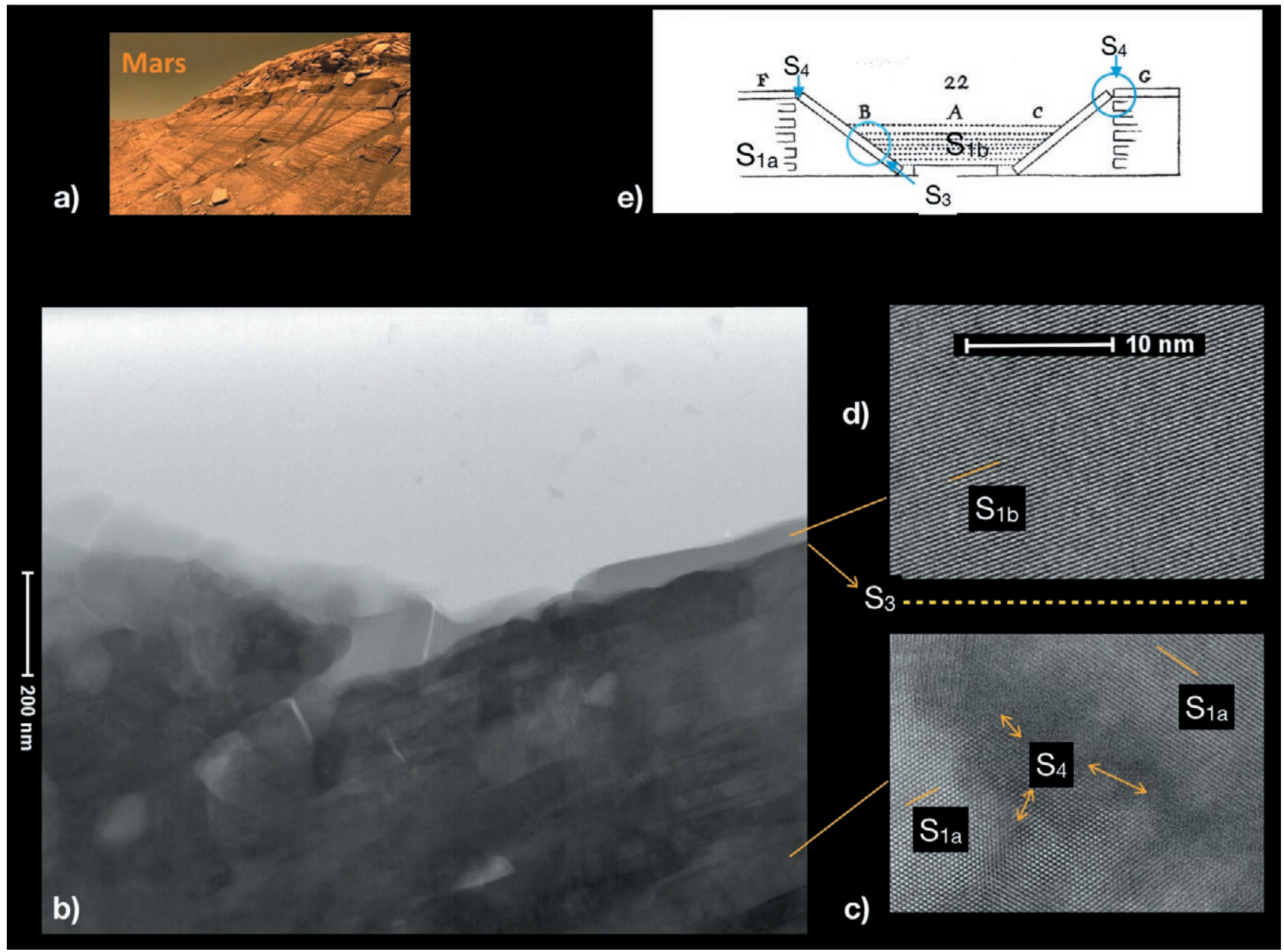

Figure 6. Stenonian time features at atomic scale in a meteorite from Mars; a) a view of Mars strata, Opportunity Rover; b) a STEM image of the shock-deformed atomic layers in baddeleyite $\left(\mathrm{S}_{1 \mathrm{a}}\right)$ reacting to undeformed zircon $\left(\mathrm{S}_{1 \mathrm{~b}}\right)$ in Mars meteorite NWA 5298; Higher magnification STEM images of the disturbed baddeleyite lattice (c), and undeformed zircon lattice (d). e) Steno's Diagram 22.

The fifth class of time features are surfaces of chemical discontinuity created by atomic movements and are distinct from the other four classes in terms of both the strength of connection to Steno and the source of their geometric form. Unlike the other feature classes, Steno did not specifically predict structures at the atomic scale in nature as this was out of observational range. Yet, as can be seen above, he allowed for their existence. They are included here as Stenonian features because Steno's writings in both the Prodromus and his later Prooemium on the topic of particle (atomic) motion and heat have been previously interpreted as descriptions of diffusion. ${ }^{97}$ This feature class differs also in regard to form in that $S_{5}$ is not a single, discrete surface but a pair of subparallel surfaces bounding a gradient of chemical

${ }^{97}$ J. M. Hansen in ref. 33. change caused by a migration of atoms after solid formation. Steno held the Cartesian view that "A natural body is an aggregate of imperceptible particles", ${ }^{98}$ and with recent advances in microscopy, geochronologists can now image and measure the three dimensional distribution of these particles, as either or both elements and isotopes, within minerals..$^{99}$ Of particular interest in zircon are the isotopes ${ }^{206} \mathrm{~Pb}$ and ${ }^{207} \mathrm{~Pb}$ which are the stable decay products of ${ }^{238} \mathrm{U}$ and ${ }^{235} \mathrm{U}$, respectively. It has recently been found that exposure of zircon to extreme heat in the Earth or in impact craters can cause $\mathrm{Pb}$ isotopes to migrate (diffuse) and pile up within the zircon lattice, thereby forming structures sensu stricto (Fig. 7). I here introduce the term 'chronostructure' for

\footnotetext{
${ }^{98}$ N. Stensen, in ref. 1 (K\&M), p. 626.
}

${ }^{99} \mathrm{~J}$. W. Valley et al., in ref. 21. 


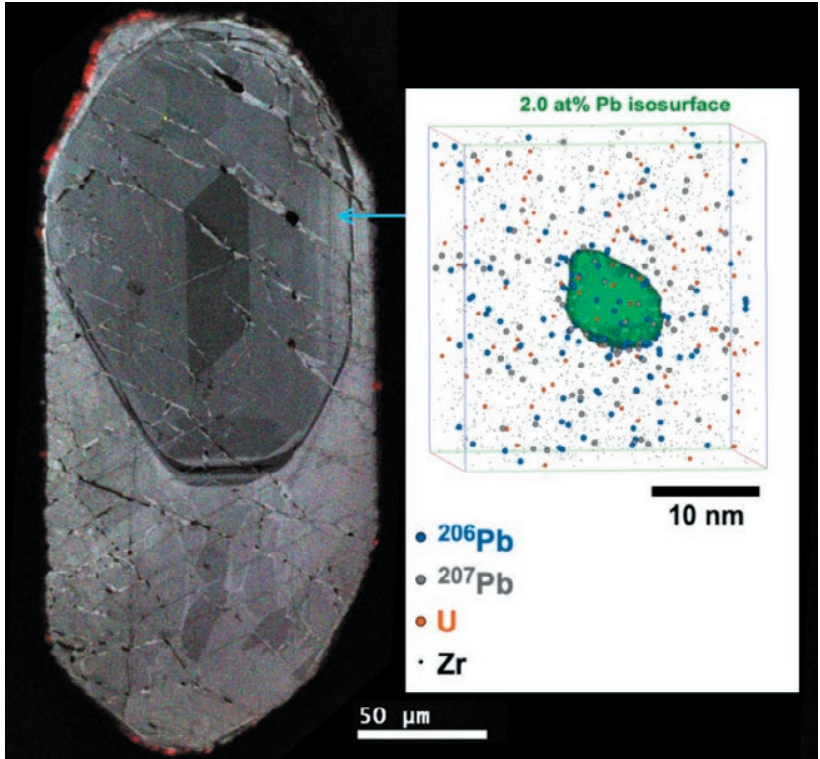

Figure 7. Example of a feature resulting from atomic diffusion (a 'chronostructure'), related to Steno's allusion to such phenomena: Left) A SEM-CL image of a shock -metamorphosed zircon from the Vredefort impact crater zircon, Right) perspective view of a three dimensional atom map of $\mathrm{Pb}$ (concentrated above $2 \%$, green surface) and $U$ isotopes imaged in a microscopic needle sampled from this grain (arrow).

this type of $\mathrm{S}_{5}$ feature as it is a concentration of atoms assembled during an event; an outcome of the universal process of elemental diffusion within or between minerals assisted by either or both deformation and temperature. ${ }^{100}$ Zircon presents a special case in that its lattice contains no $\mathrm{Pb}$ at the time of zircon crystallization due to energetic exclusion. Thus, each $\mathrm{Pb}$ atom seen today is radiogenic and itself an expression of geologic time. Zircon $\mathrm{Pb}$ chronostructures reported so far have a variety of shapes but seem to be mostly spheroidal. Examples have been documented from several regions on Earth and the Moon. ${ }^{101}$ One example can be seen in a zircon from near the centre of the Vredefort structure in South Africa where, one billion years after its formation, the largest recognized terrestrial impact event caused its $\mathrm{S}_{1}$ growth zoning to be cross-cut by $\mathrm{S}_{4}$ shock deformation features (Fig. 7). These contain nanodomains of $\mathrm{Pb}$ enriched $\sim 1000 \mathrm{x}$ above background levels due to impact-related heating and diffusion. Such chronostructures represent a new type of feature in absolute geochronology.

${ }^{100}$ E. B. Watson, E. F. Baxter, Diffusion in solid-earth Systems. Earth and Planetary Science Letters, 2007, 253, p. 307-327.

${ }^{101}$ See list of citations in G. A. Arcuri et al., in ref. 40.

\section{DISCUSSION}

This reconsideration of Steno's time features in minerals in comparison to those for other solids brings to light several themes that illuminate Steno's past and continuing contributions to mineralogy and geochronology. One is his perhaps revolutionary perception of scale invariance among the processes of solid formation in nature; an advance that is implicit in the Prodromus but not always recognized. A second theme relates to the source of his observational acuity and the provenance of his scientific philosophy which, together, enabled him to recognize geologic history. Finally, the consistent agreement between Stenonian geochronology with modern microscopy and zircon geochronology opens the door to considering Steno's large, and largely unrecognized, importance in the practice of absolute geochronology.

\section{Steno's fractal features}

What I demonstrate about Tuscany by induction from many places examined by me, so I confirm for the whole earth from the descriptions of many places set down by various writers. ${ }^{102}$

It is apparent from Steno's geochronology observations (Table 1) that he saw his results as transcending geography and spatial scale. Steno clearly believed that his findings would have global application, perhaps following the globalist thinking of Descartes which had so impressed him ${ }^{103}$. His view of local processes as a subset of universal operations of the Earth can also be seen as in line with the long philosophic history of macrocosms and microcosms which saw the human body as a facsimile of the workings of an animate Earth. ${ }^{104}$ Certainly our examples from zircon geochronology show that Stenonian features are applicable to samples from the Earth and beyond, representing stages in most of the solar system's history. Steno's implicit awareness of the fractal and scale-invariant properties of the visual records in solids, in regard to both space and time, has not been amplified in previous studies of his work, in general, and in mineralogy, in particular. His freedom of mind in respect to physical scale is illustrated in his plate of diagrams ${ }^{105}$ wherein he juxtaposes cross sections of $\mathrm{cm}$ scale crystals with two dimensional profiles through a mountainous landscape. Although cross-sectional views

\footnotetext{
${ }^{102}$ N. Stensen, in ref. 1 (K\&M), p. 654.

${ }^{103}$ D. Garber, in ref. 29.

${ }^{104} \mathrm{G}$. P. Conger, Theories of macrocosms and microcosms in the history of philosophy. New York, Columbia University Press, 1922, 142 pp.

${ }^{105}$ N. Stensen, in ref. 1 (K\&M), p. 658.
} 
of the Earth were not uncommon in the 17th century, ${ }^{106}$ Steno's clear, connection of mineral and land evolution appears to have been without precedent in European natural philosophy. A metaphor for Steno's awareness of fractal scale invariance appears in his earlier writings when praising the scope of the human mind enabled by the Creator: "Finally he will penetrate the inside of the earth and discover the hidden mysteries of the minerals. All these representations respond to a sign as if the macrocosmos laid hidden in the microcosmos". ${ }^{107}$ This accurate, fractal vision points to Steno's special abilities and method for natural philosophy.

\section{Steno's methodologic innovation}

It is proposed that Steno's achievements in the Prodromus were made possible by his innovative pairing of an innate, finely-tuned awareness of the process of visual observation and cognition with a set of Stoic ethical precepts gained earlier in his career, all coming to fruition on the Galilean soils of Florence.

Unless the mind is tranquil, it will by no means be free to apply itself to a close examination of facts which can and ought to be closely examined, and unless every least detail is noted in so far as the minuteness of the object or its intricate diversity allows, the pathway to error is downhill and very easy. ${ }^{108}$

The quality underpinning the classes of scale-invariant time features (Table 1) is that of the cognition of continuity of visual elements in regard to either chemistry or geometric orientation; but, how do we sense continuity? Neuroscience has recently shown that our visual sensory system operates with an inherent "continuity field" such that we have a short-term perceptual bias toward continuity of orientation in geometric forms. ${ }^{109}$ The timespan of the continuity field's influence on human perception was measured at 15 seconds; operating only near the observer's point of focus. It follows that accurate visual cognition of patterns in nature requires time to overcome this natural bias. There is evidence that Steno was very aware from his anatomical training and research that focused, prolonged visual inspection was requisite for accurate science (above). Moreover, he recognized the reward of careful observation in teaching and advancing science in his own time:

\footnotetext{
${ }^{106} \mathrm{~T}$. Yamada, in ref. 33.

${ }^{107}$ N. Stensen, in ref. $1(K \& M)$, p. 74.

${ }^{108}$ N. Stensen, in ref. 1 (K\&M), p. 112.

${ }^{109}$ J. Fischer, D. Whitney, Serial dependence in visual perception. Nature Neuroscience, 2014, 17, p. 38-743.
}

"Sometimes it takes years to discover that which can then be demonstrated to others in less than an hour". ${ }^{110}$ Philosophers who presaged the work of Linnaeus in the next century concentrated on "the external (and particularly the visible) structures of natural objects" 111 and, as mentioned above, Steno's examination of the internal zones of crystals was, in this regard, an innovation. Moreover, upon his arrival in Florence, Steno immediately engaged with the members of the Accademia del Cimento which followed in the 'anti-scholastic' Galilean scientific tradition of experimentation and observation, and responded by taking the middle way between scholastics and experimentalists. ${ }^{112}$ His primary instrument was human vision with which he interpreted, or abducted, ${ }^{113}$ in the language of geo-semiotics, ${ }^{114}$ meaning from the landscape. It is proposed that Steno's awareness of the need for self-discipline and time spent in observation was also guided by an awareness of the qualities of observation required if his deductions were to be deemed accurate and recognizable to others.

I decided to press with all my might in physics for what Seneca often urges strongly regarding moral precepts; he states that the best moral precepts are those which are in common use, widely accepted, and which are jointly proclaimed by all from every school. ${ }^{115}$

Perhaps one of Steno's strongest innovations in methodology was to integrate the Galilean experimentalist tradition of Florence with elements of Stoic philosophy as expressed by Seneca (above). Stoic philosophy was respected by the humanists for its systematic approach, and it is perhaps unsurprising to see it appear in Steno's work given his time as a student in Leiden, which is considered to have been the heart of Neo-Stoicism in 16th and 17th century Europe, ${ }^{116}$ and where Steno sought out the rich diversity of intellectual thought of the Dutch Golden Century. ${ }^{117}$ Steno applies the Stoic (Senecan) tradition in ethics of considering only those sensations all can agree on, and falling within the area of intersection of all scholars' perceptions. Steno's adoption of this aspect of Stoicism to his treat-

\footnotetext{
${ }^{110} \mathrm{~N}$. Stensen, in ref. 1 (K\&M), pp. 128.

${ }^{111}$ W. R. Albury, D. R. Oldroyd, in ref. 27.

${ }^{112} \mathrm{~J}$. Bek-Thomsen, in ref. 8.

${ }^{113}$ J. E. H. Smith, Thinking from traces. Nicolas Steno's palaeontology and the method of science, in ref. 8, p. 177-200.

${ }^{114}$ V. R. Baker, Geosemiosis. GSA Bulletin, 1999, 111, p. 633-645.

${ }^{115}$ N. Stensen, in ref. 1 (K\&M), p. 626.

${ }^{116}$ J. Lagrée, Justus Lipsius and neostoicism, in The Routledge handbook of the Stoic tradition (Ed. J. Sellars), Taylor \& Francis Group.

${ }^{117}$ E. Jorink, Modus politicus vivendi. Nicolaus Steno and the Dutch (Swammerdam, Spinoza and Other Friends), 1660-1664, in ref. 8, p. $13-44$.
} 
ment of the results of his visual, Galilean experiments in the field allowed him to distill and communicate his uniquely systematic interpretation of natural history.

\section{Steno and modern geochronology}

To recognize the temporal in the spatial - nobody had done that before Stensen -, from the whole rock to read a dynamic course of time, has since then become and remained the main object of scientific geology. ${ }^{118}$

It can be argued that Galilean science, and the Prodromus, are similarly rooted in the sensation and measurement of time. In 1654, Viviani reported that a youthful Galileo used the period of his heartbeat to recognize the isochronous swings of a lantern through the space beneath the Duomo of Pisa, ${ }^{119}$ leading, ultimately, to his famous pendulum studies of the strength and orientations of gravity. One might sense echoes of this approach in the Prodromus in which Steno recognized the geometric tracings of time in solids using his highly attuned perception of discontinuity and its, embedded component of time. Steno extended his extraordinary pattern recognition, likely refined through his years of anatomical research, to further place an order on sets of visible features, as in his reconstruction of Tuscan geology; "obvious inequalities in the present surface contain within themselves clear indications of various changes, which I shall review in inverse order, working back from the most recent to the first". ${ }^{120}$ In both strata and minerals (e.g. Fig. 1), Steno was thus the first to so methodically order past geologic events based on field experiments, setting the relative geochronology framework which would be employed by Holmes in his proof-of-concept of absolute geochronology more than two centuries later. Stenonian method continues to be vital in geochronology as technical advances enable sampling of eversmaller volumes and atom-scale observation of elements, isotopes and chronostructures becomes more widely applied; for it is axiomatic that absolute geochronology is dependent on the length-scale of sampling owing to Holmes' principle of the closed chemical system. Conversely, Steno's spatial system of relative geochronology is scale-invariant in respect of both space and time. Steno's classes of visible features of production and modification therefore continue to serve as an independent, intensive, time measurement system for interpreting and checking the accuracy of absolute, extensive, geochro-

\footnotetext{
${ }^{118} \mathrm{~K}$. von Bülow, in ref. 5.

${ }^{119} \mathrm{~S}$. Gattei, On the life of Galileo: Vivianis historical account and other early biographies. Princeton University Press, 2019, p. 440.

${ }^{120}$ N. Stensen, in ref. 1 (K\&M), pp. 653.
}

nology age measurements to allow us to achieve a more accurate geochronology.

\section{CONCLUSION}

Steno's Prodromus has been recognized by many scholars as a brilliant, though loosely organized, advance in human observation and perception of records of geologic time in solids. A reconsideration and classification of Steno's writings on processes deduced from solids, and especially atomistic processes in mineral bodies, in terms of visual time features brings to light additional Stenonian advances. Successful comparison of Steno's time features with electron microscopy down to atom scale help demonstrate Steno's implicit appreciation of the fractal, scale-invariant nature of time features. Steno's methodologic advances are also discussed; with the proposal that it was Steno's combination of his awareness of the precision and accuracy of the human visual system with Stoic, and particularly Senecan, precepts in ethics which propelled his remarkable achievements in the rich, Galilean scientific environment of Florence. Finally, it is argued that the intensive quality of Stenonian geochronology causes it to be an invaluable check on the accuracy of extensive, absolute geochronologic age values, thus asserting the modernity of Steno in the geochronology of solids from Earth and beyond.

\section{ACKNOWLEDGEMENT}

I gratefully acknowledge helpful reviews of earlier versions of this manuscript by Yuri Amelin and Jens Morten Hansen. Many thanks to Eric Jorink for his review and helpful directions to Stoic literature. Nuno Castel-Branco is thanked for assistance accessing Steno literature early in the pandemic. Gabriel Arcuri is thanked for assistance with Figure 7. The author gratefully acknowledges his many collaborators associated with the microscopy presented here. Helpful editorial comments by G. D. Rosenberg are very gratefully acknowledged. Stefano Dominici is especially thanked for patient and supportive reviews and guidance, important Steno references, and direction in navigating historical science literature and conventions. NASA Apollo 17 astronauts and mission scientists are sincerely thanked for lunar photograph in Fig 5. NASA/JPL/Cornell are acknowledged for the Burns Cliff, Endurance Crater, Opportunity Rover image in Fig. 6. Participants in the Oct. 2019 symposium at the University of Florence are thanked for many conversations and generous sharing of their wealth of Steno knowledge. 